\title{
Health inequities in the diagnosis and outcome of sepsis in Argentina: a prospective cohort study
}

Elisa Estenssoro ${ }^{1 *}$, Cecilia I. Loudet ${ }^{1}$, Vanina S. K. Edul ${ }^{2}$, Javier Osatnik ${ }^{3}$, Fernando G. Ríos ${ }^{4}$, Daniela N. Vásquez ${ }^{5}$, Mario O. Pozo ${ }^{6}$, Bernardo Lattanzio ${ }^{7}$, Fernando Pálizas ${ }^{6}$, Francisco Klein ${ }^{8}$, Damián Piezny ${ }^{4}$, Paolo N. Rubatto Birri ${ }^{9}$, Graciela Tuhay ${ }^{8}$, Anatilde Díaz ${ }^{10}$, Analía Santamaría ${ }^{11}$, Graciela Zakalik ${ }^{12}$, Arnaldo Dubin ${ }^{9}$ and investigators of the SATISEPSIS Group

\begin{abstract}
Background: Socioeconomic variables impact health outcomes but have rarely been evaluated in critical illness. Low- and middle-income countries bear the highest burden of sepsis and also have significant health inequities. In Argentina, public hospitals serve the poorest segment of the population, while private institutions serve patients with health coverage. Our objective was to analyze differences in mortality between public and private hospitals, using Sepsis-3 definitions.

Methods: This is a multicenter, prospective cohort study including patients with sepsis admitted to 49 Argentine ICUs lasting 3 months, beginning on July 1, 2016. Epidemiological, clinical, and socioeconomic status variables and hospital characteristics were compared between patients admitted to both types of institutions.

Results: Of the 809 patients included, 367 (45\%) and 442 (55\%) were admitted to public and private hospitals, respectively. Those in public institutions were younger (56 \pm 18 vs. $64 \pm 18 ; p<0.01$ ), with more comorbidities (Charlson score 2 [0-4] vs. 1 [0-3]; $p<0.01$ ), fewer education years (7 [7-12] vs. 12 [10-16]; $p<0.01$ ), more frequently unemployed/informally employed (30\% vs. 7\%; $p<0.01$ ), had similar previous self-rated health status (70 [50-90] vs. 70 [50-90] points; $p=0.30$ ), longer pre-admission symptoms (48 [24-96] vs. 24 [12-48] h; $p<0.01$ ), had been previously evaluated more frequently in any healthcare venue (28 vs. 20\%; $p<0.01$ ), and had higher APACHE II, SOFA, lactate levels, and mechanical ventilation utilization. ICU admission as septic shock was more frequent in patients admitted to public hospitals (47 vs. 35\%; $p<0.01$ ), as were infections caused by multiresistant microorganisms. Sepsis management in the ICU showed no differences. Twenty-eight-day mortality was higher in public hospitals (42\% vs. 24\%; $p<0.01)$ as was hospital mortality (47\% vs. 30\%; $p<0.01$ ). Admission to a public hospital was an independent predictor of mortality together with comorbidities, lactate, SOFA, and mechanical ventilation; in an alternative prediction model, it acted as a correlate of pre-hospital symptom duration and infections caused by multiresistant microorganisms.

Conclusions: Patients in public hospitals belonged to a socially disadvantaged group and were sicker at admission, had septic shock more frequently, and had higher mortality. Unawareness of disease severity and delays in the health system might be associated with late admission. This marked difference in outcome between patients served by public and private institutions constitutes a state of health inequity.
\end{abstract}

Keywords: Sepsis-3, Septic shock, Health inequity, Sepsis awareness, Socioeconomic status, SES

\footnotetext{
* Correspondence: estenssoro.elisa@gmail.com

${ }^{1}$ Servicio de Terapia Intensiva, Hospital Interzonal de Agudos San Martin de

La Plata, Calle 42 No.577, 1900 La Plata, Buenos Aires, Argentina

Full list of author information is available at the end of the article
}

(c) The Author(s). 2019 Open Access This article is distributed under the terms of the Creative Commons Attribution 4.0 International License (http://creativecommons.org/licenses/by/4.0/), which permits unrestricted use, distribution, and reproduction in any medium, provided you give appropriate credit to the original author(s) and the source, provide a link to the Creative Commons license, and indicate if changes were made. The Creative Commons Public Domain Dedication waiver (http://creativecommons.org/publicdomain/zero/1.0/) applies to the data made available in this article, unless otherwise stated. 


\section{Introduction}

While there is a significant body of knowledge about socioeconomic determinants of health in chronic disease and in all-cause mortality [1-4], how these factors impact the outcomes of critical illness still remains mostly unknown. The information, however, is slowly beginning to emerge: it has been demonstrated that decreasing Gross National Income (GNI) per capita is associated with rising mortality in ICU patients in general and also in patients with ARDS [5-7]. Sepsis is responsible for approximately 5.3 million deaths annually worldwide, but this data likely underestimates true global figures as it is extrapolated from high-income countries (HICs). Low- and middleincome countries (LMICs), the most populated regions of the world, bear the highest burden of sepsis [8-10]. LMICs face their own challenges: microorganisms causing sepsis differ from those of high-income countries, clinical outcomes might be poorer, and in LMICs, the provision of critical care could be suboptimal [10-15]. Most importantly, within these countries, profound inequities, defined as systematic, unjust, and preventable differences in determinants of health, such as socioeconomic status (SES), demographics, and geography, might create a health gradient that ultimately affects outcomes for various population subgroups [16].

Additionally, health systems are usually fragmented, consisting of an overloaded public sector serving the poor, social security agencies for formal workers, and a private sector for the wealthy [17-20]. This complex structure leads to further social segregation, given that the healthcare process perpetuates the differences in SES.

The SATISEPSIS prospective cohort study in 49 ICUs in Argentina validated Sepsis-3 definitions [21] in an upper middle-income country and showed epidemiologic characteristics, management, outcomes, and predictors of mortality [22]. A key secondary purpose of SATISEPSIS was to examine differences in outcomes and their determinants in patients admitted to the different health subsectors, which is explored in this study. Our hypothesis was that higher mortality, usually ascribed to admission to public hospitals [23-25], was attributable to a more advanced-and, as such, more severe-state of the disease on admission. We also sought to identify the independent prognostic factors that could lead to this negative outcome.

Some of the results of these studies have been previously reported in the form of an abstract [26].

\section{Methods}

Detailed methods and the main results for SATISEPSIS have been published elsewhere [22]. Briefly, SATISEPSIS was a national, multicenter, prospective cohort study lasting 3 months, beginning on July 2, 2016. The study was conceived by the Argentine Society of Intensive
Care (SATI: Sociedad Argentina de Terapia Intensiva) and partially sponsored by the Argentine National Ministry of Health. The primary aims were to characterize the epidemiology and outcome of sepsis in an upper middleincome country using the Sepsis-3 definitions and to assess its prognostic validity. The study was approved by each hospital's Institutional Review Board, and informed consent was signed by patients or their relatives.

Patients included were $\geq 18$ years, admitted to participating ICUs with a suspected infection that triggered blood cultures and/or other body fluid sampling, and administration of antibiotics within $24 \mathrm{~h}$. Patients with infections developed during ICU stay were also considered.

Patients were assigned to the categories of infection, sepsis, or septic shock according to Sepsis-3 definitions [21].

On ICU admission, recorded data were epidemiological data, Charlson score, self-rated overall health status previous to the current disease (Euro-QoL visual analogue scale [EQ-VAS], from 100 points [best possible status] to 0) [27], duration of infection symptoms, home-to-hospital distance, years of education, occupation, previous evaluation in another healthcare venue for the current disease, APACHE II and SOFA scores [28], presence of systemic inflammatory response syndrome (SIRS), presumed site of infection, and origin of infection. If patients were unable to respond, data were provided by the next of kin. Other measured variables were serum lactate; vasopressor use; fluid requirement; time to administration of antimicrobials and adequacy, according to isolated microorganisms; presence of highly resistant microorganisms; and organizational characteristics of each participating center.

For this study, the main comparisons were between patients admitted to public or private hospitals. Public institutions comprise two sector blocks: hospitals dependent on the national or provincial Ministry of Health and others belonging to the social security system; they serve the poorest segment of the population and the formal workers, respectively [29]. For this analysis, they were merged into the "Public" category, as has been suggested [19]. In contrast, private hospitals are for-profit or nonprofit privately funded institutions, which serve patients with private health insurance or who pay for services out of pocket. The primary outcome was hospital mortality.

\section{Statistical analysis}

Data are presented as proportions, mean and standard deviations, or median and [0.25-0.75] percentiles. Differences between patients admitted to public and private hospitals were analyzed with chi-square or Fisher's tests or $t$ or Wilcoxon rank sum tests, as appropriate. Our aim was to determine if there was an association between mortality and the type of hospital. Variables differing between survivors and nonsurvivors with a $p<0.10$ in 
bivariable analysis were entered into two different multivariable logistic regression models, one which included the public/private category and the other which did not. Calibration was assessed using the Hosmer-Lemeshow test. A receiver operating characteristic (ROC) curve was constructed to evaluate model discrimination. To avoid bias introduced by missing data and assuming they were missing at random, the analysis of the primary outcome was replicated after multiple imputation.

Data were analyzed with Stata 14.0 (StataCorp LP, College Station, TX, USA).

\section{Results}

Overall recruitment was 809 patients. Of the 49 participating ICUs, 23 (43\%) belonged to the public sector and $26(57 \%)$ to the private, and included 367 (45\%) and 442 (55\%) patients, respectively (Fig. 1). Only 2 of the 23 hospitals of the public system corresponded to the social security system.

Compared to patients in private hospitals, patients in public institutions were significantly younger $(56 \pm 18$ vs. $64 \pm 18 ; p<0.01)$, had lower BMI (26 [23-29] vs. 27 [24-31]; $p<0.01$ ), had more comorbidities (Charlson score $2[0-4]$ vs. $1[0-3]$ points; $p<0.01)$, had alcoholrelated problems ( $22 \%$ vs. $7 \%$; $p<0.01)$, had fewer years of education (7 [7-12] vs. 12 [10-16]; $p<0.01)$, and were more frequently unemployed or had illegal jobs (30\% vs. $7 \% ; p<0.01)$. The perception of the self-rated overall health status prior to the present disease was similar, according to EQ-VAS. With respect to sepsis/ septic shock, the duration of pre-admission symptoms was twice that of patients in public hospitals (48 [24-96] vs. 24 [12-48] h; $p<0.01$ ), and they had been evaluated more frequently in any healthcare venue before admission $(28 \%$ vs. $20 \% ; p<0.01)$, compared to patients in private hospitals. Home-to-hospital distances were similar for both groups. All comparisons are shown in Table 1.

Patients admitted to public hospitals had higher APACHE II, septic shock, requirement of mechanical ventilation, and lactate levels than patients in private hospitals $(p<0.01$ in all cases) (Table 2). There were no differences between groups in time to receiving the first antibiotic dose or administration of a fluid bolus of $30 \mathrm{ml} / \mathrm{kg}$. Infections due to multiresistant microorganisms were significantly more frequent in public hospitals than in private ones.

Twenty-eight-day mortality was $42 \%$ in public hospitals (vs. $24 \%$ in private; $p<0.01$ ); hospital mortality was respectively $47 \%$ vs. $30 \%(p<0.01)$; Kaplan-Meier estimates of survival were also different (log-rank test $p<0.01$; Fig. 2). No differences in the length of mechanical ventilation or of ICU and hospital stay were recorded.

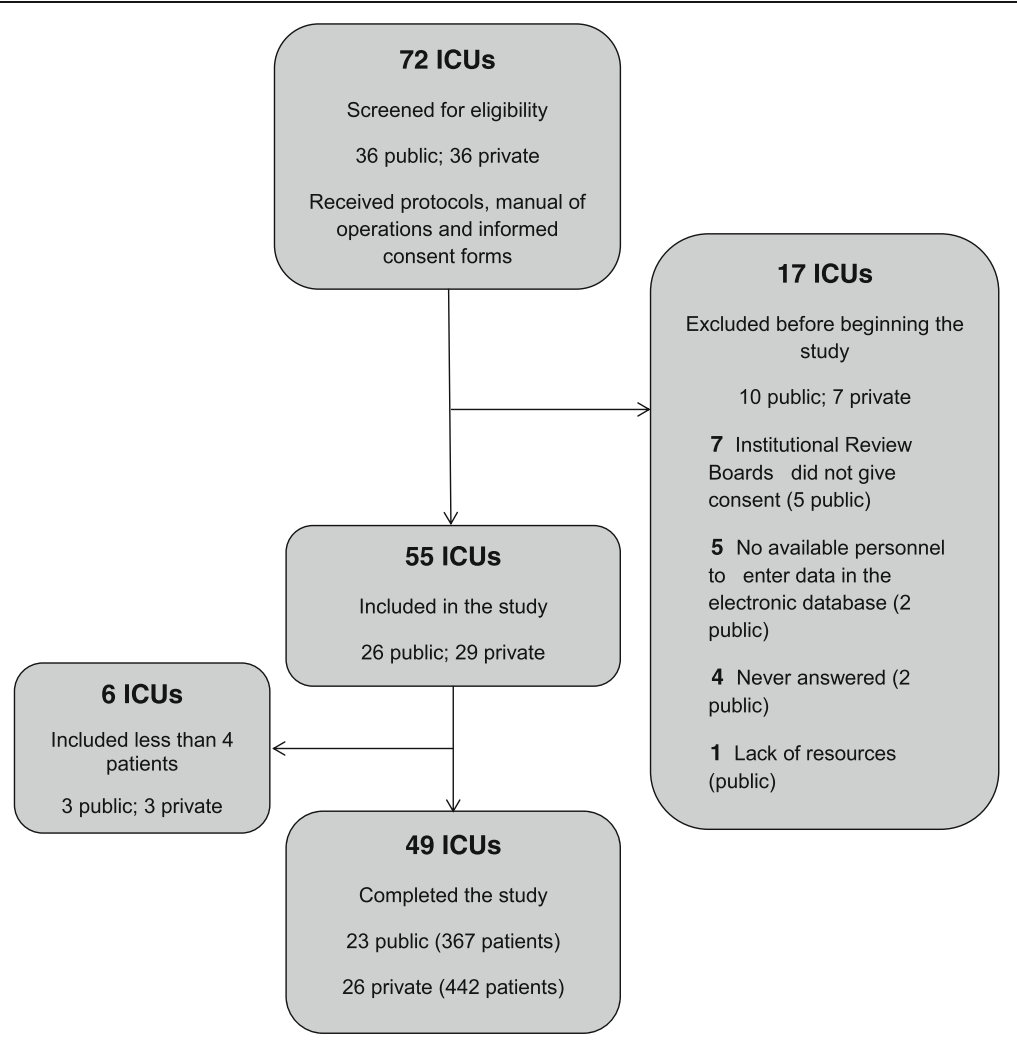

Fig. 1 Flow chart of the SATISEPSIS study and distribution of ICUs according to their location in public and private hospitals 
Table 1 Patient epidemiological characteristics, socioeconomic status variables, perception of previous health status, and duration of symptoms before admission

\begin{tabular}{|c|c|c|c|c|}
\hline & Public hospitals $N=23$ & Private hospitals $N=26$ & Missing values & $p$ value \\
\hline Number of patients & $367(45)$ & $442(55)$ & & \\
\hline Age (years) & $\begin{array}{l}56 \pm 18 \\
N=367\end{array}$ & $\begin{array}{l}64 \pm 18 \\
N=442\end{array}$ & 0 & $<0.01$ \\
\hline Female gender & $157 / 367(43)$ & 197/442 (55) & 0 & 0.61 \\
\hline Body mass index $\left(\mathrm{kg} / \mathrm{m}^{2}\right)$ & $\begin{array}{l}26[23-29] \\
N=341\end{array}$ & $\begin{array}{l}27[24-31] \\
N=426\end{array}$ & 42 & $<0.01$ \\
\hline Years of education & $\begin{array}{l}7[7-12] \\
N=226\end{array}$ & $\begin{array}{l}12[10-16] \\
N=326\end{array}$ & 257 & $<0.01$ \\
\hline Occupation $^{\S}$ & & & 0 & $<0.01$ \\
\hline Legally employed or health-insured & $241 / 367(66)$ & $397 / 442(90)$ & & \\
\hline Illegal worker or unemployed & $126 / 367(34)$ & $45 / 442(10)$ & & \\
\hline Charlson score & $\begin{array}{l}2[0-4] \\
N=361\end{array}$ & $\begin{array}{l}1[0-3] \\
N=433\end{array}$ & 15 & $<0.01$ \\
\hline $\begin{array}{l}\text { Self-perception of previous health state } \\
\text { EQ-VAS* }\end{array}$ & $\begin{array}{l}70[50-90] \\
N=226\end{array}$ & $\begin{array}{l}70[50-90] \\
N=350\end{array}$ & 233 & 0.30 \\
\hline Smoking habit & $110 / 358(31)$ & $114 / 430(27)$ & 21 & 0.19 \\
\hline Alcohol-related problem & $77 / 358(22)$ & $30 / 430(7)$ & 21 & $<0.01$ \\
\hline Distance to the hospital (km) & $\begin{array}{l}0[0-10] \\
N=353\end{array}$ & $\begin{array}{l}1[0-10] \\
N=431\end{array}$ & 25 & 0.13 \\
\hline Duration of sepsis symptoms (hours) & $\begin{array}{l}48[24-96] \\
N=264\end{array}$ & $\begin{array}{l}24[12-48] \\
N=360\end{array}$ & 185 & $<0.01$ \\
\hline Previous evaluation in any healthcare venue" & $98 / 356(28)$ & $85 / 433(20)$ & 20 & $<0.01$ \\
\hline
\end{tabular}

Data are presented as $n(\%)$, mean \pm standard deviation, or $\mathrm{mdn}[0.25-0.75]$ percentiles, unless specified

5The occupation category of "legally employed or health-insured" comprises patients with legal jobs, students, retired, and homemakers

*EQ-VAS: EuroQol visual analogue scale (from 100 points [best health state to 0 worst] self-evaluated health state, previously to the diagnosis of sepsis)

"Includes primary practices, lower-complexity hospitals, or major hospitals

ICU bed number was similar in public and private hospitals, but human resources (nurse-to-patient-ratio, number of board-certified specialists and of residents) were higher in public hospitals (Additional file 1: Table S1).

Localization of sites of infection was similar across groups (Additional file 1: Table S2).

With regard to independent determinants of mortality (Table 3 and Additional file 1: Table S3), variables related to higher comorbid disease, and higher severity of acute disease such as SOFA score, increasing lactate levels, requirement of mechanical ventilation, and admission to a public hospital, were associated to higher mortality, with excellent model calibration and discrimination. This is shown in model 1 . However, when other relevant covariates such as duration of previous symptoms and infection by multiresistant microorganisms were tested in the model, admission to a public hospital ceased to have a significant association with mortality-acting as a correlate for the last two variables (Table 3 ). These results were consistent after performing multiple imputation for missing values in the variables of interest (Additional file 1: Tables S4 and S5).

\section{Discussion}

In this large, prospective cohort study carried out in Argentina in patients with sepsis and septic shock, admission to a public hospital was associated with higher mortality compared to admission to a private institution. In LMICs, this phenomenon has already been reported in sepsis and critically ill obstetric patients [23-25]. The difference in the main outcome $(47 \%$ vs. $30 \%$ mortality for public vs. private hospitals) was striking and reflected that patients admitted to public hospitals-although younger-were more acutely ill, had more underlying diseases, had a longer period of sepsis symptoms, and suffered from more frequent infections by highly resistant microorganisms.

Socioeconomic differences might have impacted outcomes indirectly since admission to hospitals belonging to the public health subsector can be considered a proxy of low SES, given that they serve uninsured, socially disadvantaged groups. In accordance with this, patients from public hospitals in our study had significantly fewer years of education (a difference of 5 years), lower BMI, more alcohol-related problems, and higher rates of unemployment or illegal jobs. Furthermore, public hospitals 
Table 2 Patient characteristics at admission, outcomes, and hospitals' characteristics

\begin{tabular}{|c|c|c|c|c|}
\hline & Public hospitals' ICUs $=23$ & Private hospitals' ICUs $=26$ & Missing values & $p$ value \\
\hline Number of patients & $367(45)$ & $442(55)$ & & \\
\hline \multicolumn{5}{|l|}{ Patient characteristics } \\
\hline Patient origin upon entry to study & & & 23 & 0.20 \\
\hline Community & 192/354 (54) & 239/432 (55) & & \\
\hline Hospital & $113 / 354(32)$ & 138/432 (32) & & \\
\hline ICU & $40 / 354(11)$ & 40/432 (9) & & \\
\hline Third-level institution & $5 / 354(1)$ & 14/432 (3) & & \\
\hline Unknown & $4 / 354(1)$ & $1 / 432(0)$ & & \\
\hline APACHE ॥ & $\begin{array}{l}20 \pm 9 \\
N=323\end{array}$ & $\begin{array}{l}18 \pm 7 \\
N=419\end{array}$ & 67 & $<0.01$ \\
\hline SOFA & $\begin{array}{l}8[5-11] \\
N=354\end{array}$ & $\begin{array}{l}6[4-9] \\
N=433\end{array}$ & 22 & $<0.01$ \\
\hline Lactate (mmol/L) & $\begin{array}{l}2[2-4] \\
N=315\end{array}$ & $\begin{array}{l}2[1-3] \\
N=404\end{array}$ & 90 & $<0.01$ \\
\hline Admission with septic shock & $172 / 367(47)$ & 155/442 (35) & 0 & $<0.01$ \\
\hline Use of mechanical ventilation & $257 / 367(70)$ & $211 / 440(48)$ & 2 & $<0.01$ \\
\hline Requirement of a fluid bolus of $30 \mathrm{ml} / \mathrm{kg}$ & $264 / 367(72)$ & 309/442 (70) & 0 & 0.47 \\
\hline Time to first antibiotic dose (hours) & $\begin{array}{l}2[1-3] \\
N=301\end{array}$ & $\begin{array}{l}2[1-3] \\
N=398\end{array}$ & 10 & 0.47 \\
\hline Antibiotic administration & & & 110 & 0.31 \\
\hline Inadequate & $39(13)$ & $43(11)$ & & \\
\hline Adequate & $168(56)$ & $245(62)$ & & \\
\hline Negative cultures (\%) & $94(31)$ & $110(28)$ & & \\
\hline Infections by highly resistant microorganismst & $93 / 367(26)$ & $85 / 442(19)$ & 0 & 0.02 \\
\hline \multicolumn{5}{|l|}{ Patient outcomes } \\
\hline Length of mechanical ventilation (days) & $\begin{array}{l}8[4-15] \\
N=338\end{array}$ & $\begin{array}{l}8[3-16] \\
N=407\end{array}$ & 64 & 0.44 \\
\hline Length of ICU stay (days) & $\begin{array}{l}10[4-20] \\
N=359\end{array}$ & $\begin{array}{l}9[4-18] \\
N=430\end{array}$ & 20 & 0.20 \\
\hline Length of hospital stay (days) & $\begin{array}{l}18[9-37] \\
N=337\end{array}$ & $\begin{array}{l}19[9-31] \\
N=390\end{array}$ & 82 & 0.22 \\
\hline 28-day mortality & $153 / 367(42)$ & 107/442 (24) & 0 & $<0.01$ \\
\hline Hospital mortality & $172 / 367(47)$ & $131 / 442(30)$ & 0 & $<0.01$ \\
\hline
\end{tabular}

Data are presented as $n$ (\%), mean \pm standard deviation, or mdn [0.25-0.75] percentiles, unless specified APACHE II Acute Physiologic And Chronic Health Evaluation score, SOFA Sequential Organ Failure Assessment

tHighly resistant microorganisms include methicillin-resistant Staphylococcus aureus, vancomycin-resistant Enterococcus, Pseudomonas aeruginosa, Acinetobacter baumannii, and $\beta$-lactamase-producing Klebsiellae

are usually underfinanced by national or local health ministries [29]. Differential outcomes related to SES are not exclusive to LMICs: in HICs like England, a higher "deprivation index" (calculated after education, employment, income, disabilities, and other variables) has been related to increased ICU mortality [30]. In the USA, in a nationwide retrospective cohort analysis of patients with sepsis, those with the lowest median income level were younger, less likely to be Caucasian, had lower health insurance coverage, and had higher mortality, compared to residents of the highest income quartile [31]. In other HICs, low SES has also been associated with more severe disease upon ICU admission and higher comorbid conditions [32, 33].

The fact that patients from public hospitals had experienced $48 \mathrm{~h}$ of sepsis-related symptoms before having been admitted (vs. $24 \mathrm{~h}$ from those in private institutions) is remarkable and deserves close attention. This finding may be explained using the conceptual framework of "the three-delay model" developed to explain the obstacles in obtaining appropriate obstetric care in low-income countries [34]. This model has recently been applied to evaluate emergency care given that LMICs bear a high burden of emergencies [35]. The first barrier 


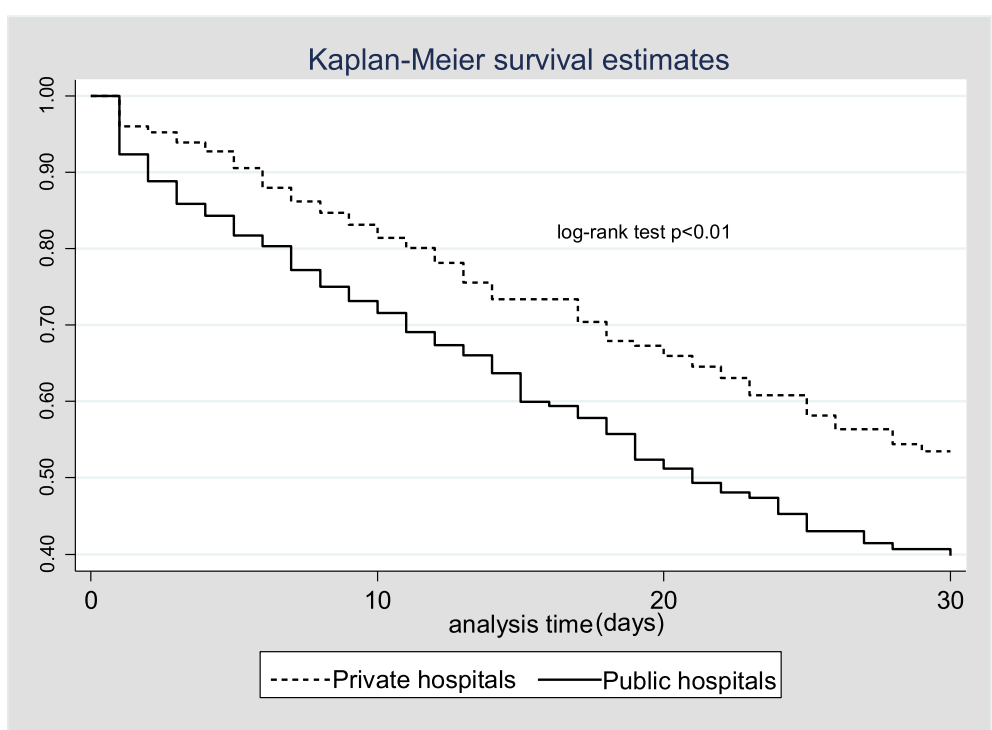

Fig. 2 Differences in time to survival in patients admitted to public and private hospitals

that produces a delay in diagnosis and treatment is patient lack of awareness of a potentially severe condition; it is ascribed to educational and cultural factors [34, 35]. In our study, educational achievements were notably lower in patients in the public health subsector, likely contributing to their inability to recognize illness severity and subsequently to the higher frequency of admission with septic shock.

Patients with low education might also be unaware that they have chronic medical conditions. In this study, despite their significantly higher Charlson score, patients from public hospitals rated self-perception of comorbidities equal to that of patients from private institutions. A "dose-response" relationship between educational attainment and health is well-established in the literature $[16,36]$.

In the 3-delay conceptual framework, the second delay is access to healthcare facilities, which includes geographical distance and transportation issues. Of note, in Argentina, patients can be admitted directly to public hospitals without previous evaluation in clinics. We did not find differences in home-to-hospital distance between groups, perhaps because most patients lived in big cities, reflecting the unbalanced distribution of population in Argentina-which is 92\% urban [37]. However, availability of patient transportation might have differed between

Table 3 Independent determinants of mortality by means of logistic regression analysis

\begin{tabular}{|c|c|c|}
\hline \multirow[t]{2}{*}{ Variable } & \multicolumn{2}{|l|}{$\begin{array}{l}\text { Multivariable analysis } \\
\text { OR [95\%Cl] }\end{array}$} \\
\hline & Model 1 & Model 2 \\
\hline Charlson score & $1.22[1.13-1.33] p<0.01$ & $1.29[1.16-1.42] p<0.01$ \\
\hline \multicolumn{3}{|l|}{ Previous health state (EQ-VAS) } \\
\hline Previous duration of disease & & $1.005[1.004-1.010] p=0.047$ \\
\hline Lactate (mmol/L) & $1.20[1.10-1.31] p<0.01$ & $1.28[1.15-1.41] p<0.01$ \\
\hline SOFA $24 \mathrm{~h}$ & $1.13[1.07-1.20] p<0.01$ & $1.14[1.06-1.22] p<0.01$ \\
\hline Mechanical ventilation utilization & $8.61[5.21-14.23] p<0.01$ & $12.91[6.84-24.35] p<0.01$ \\
\hline Highly resistant microorganismst & & $1.76[1.05-2.95] p=0.032$ \\
\hline Admission to a public hospital & $1.47[1.00-2.17] p=0.048$ & $1.24[.78-1.96] p=0.360$ \\
\hline
\end{tabular}

Model calibration and discrimination: model 1, which includes public hospital as a variable, has an area under the receiver operating characteristic (ROC) curve of $0.83[0.80-0.86]$, with a Hosmer-Lemeshow test of 0.99 . For model 2, values are 0.86 [0.83-0.89], respectively. Bivariate analysis is presented in Additional file 1: Table $\mathrm{S} 2$

$O R$ odds ratio, $C I$ confidence interval, EQ-VAS EuroQol visual analogue scale (from 100 points [best health state to 0 worst] self-evaluated health state, previously to the diagnosis of sepsis), SOFA Sequential Organ Failure Assessment

tHighly resistant microorganisms include methicillin-resistant S. aureus, vancomycin-resistant Enterococcus, P. aeruginosa, A. baumannii, and

$\beta$-lactamase-producing Klebsiellae 
both types of hospitals; it has been considered a surrogate of health insurance [38].

Lastly, it is worth mentioning that the arrival at a healthcare venue does not imply receiving immediate diagnosis and treatment. Patients in public hospitals reported antecedent visits to health clinics without inpatient admission more frequently than patients in private hospitals. Lack of recognition of communityacquired sepsis might have contributed to this.

Lack of awareness of sepsis in healthcare providers has been reported in an LMIC like Brazil, where patients admitted to public hospitals with sepsis exhibited higher mortality compared to those admitted to private hospitals. The authors ascribed this worsened prognosis to delay in diagnosis and thereafter in receiving appropriate treatment [39]. General lack of knowledge of physicians and healthcare personnel about sepsis occurs worldwide [40-42]; these situations might lead to delayed treatment and progression to more severe forms of disease (i.e., septic shock). Notwithstanding this, regarding sepsis management in the ICU, patients obtained similar treatment in both types of hospitals. Indeed, median time to antibiotic administration at sepsis recognition was $2 \mathrm{~h}$, in keeping with the 3-h bundle of the Surviving Sepsis Campaign; still, this was longer than the $1-h$ period recently recommended, which underscores the concept of sepsis as a medical emergency [43-45]. Initial fluid management (administration of a $30 \mathrm{ml} / \mathrm{kg}$ bolus) and the proportion of patients with negative cultures/adequate/inadequate antibiotics also did not differ. Infections by multiresistant microorganisms were more frequent in public hospitals, and this was an independent predictor of mortality. Most unexpectedly, this complication could not be attributed to personnel shortage as the public hospitals recorded higher physician-to-patient and nurse-to-patient ratios. However, turnover is frequent in the public system, as described in other LMICs [25], and may be associated with inappropriate care. Beyond the numbers of healthcare personnel, processes of care are what seem to impact clinical outcomes [46]. We did not record the use of protocols in this study; nevertheless, in Latin-American ICUs, their utilization is suboptimal [17]. A differential adoption of hand-washing practices or other quality improvement initiatives between both types of institutions might explain our findings. What is more, in a recent survey of 735 Latin-American intensivists, the evaluation of satisfactory conditions to treat septic shock was lower in public hospitals due to insufficient technology, laboratory support, imaging resources, and drug availability [47].

Solutions are complex, since educational level and occupation/employment are components of SES together with income and wealth [48], all factors deeply affected in the population served by public institutions. Nevertheless, some factors are modifiable, thus establishing new targets for public health intervention. The World Health Organization has instructed its country members to increase awareness of sepsis both in the general public and in healthcare workers through public campaigns, educational activities, safety patient projects, and advocacy efforts-highlighting sepsis as a preventable but timesensitive disease $[49,50]$. Such initiatives have already been implemented in many countries [51,52], yet not in Argentina. To date in Argentina, there have been campaigns targeting vaccinations, AIDS, and seasonal infectious diseases like measles, influenza, hantavirus pulmonary syndrome, dengue, zika, and leptospirosis via TV advertisements, billboards, street advertising, and outreach programs [53]. As the WHO recommends, health authorities could increase awareness by introducing the term "sepsis" as a comprehensive concept and using it to communicate with population at large as well as patients, families, and healthcare workers. The WHO also suggests fostering activities on September 13, which has been established as World Sepsis Day [49].

Within the ICU, the development of local quality improvement programs to increase compliance with the Surviving Sepsis Campaign bundles might improve the situation since they are associated with decreased mortality when implemented $[43,54,55]$. A word of caution is necessary since belonging to a South American country, a public hospital, or an LMIC is related to low compliance with campaign bundles [23, 56]. This low compliance underscores deep deficiencies in terms of resources, training, ICU beds, drugs and devices, and low adherence to protocols [17]. It is our hope that this study will be considered a step towards addressing the problem of sepsis in Argentina.

This study has limitations. Center participation was voluntary and might bias results. However, we sampled 7.2\% of all Argentine ICUs (49/681), and the proportion between public and private institutions was consistent with the national distribution. We did not measure income directly, but we recorded other determinants of SES such as education level and occupation. We were not able to demonstrate an independent effect of inequity markers on mortality, such as education or employment status. However, it is possible that these variables reflecting deprivation states need to be assessed comprehensively in an index including further indicators, instead of isolated variables [30, 32, 33]. We consider that solely being admitted to a public hospital reflects the variables related to health inequities. Our data might not be generalizable to septic patients admitted in other settings such as EDs or wards.

Strengths of the study consist in its prospective design and the comprehensive evaluation of relevant variables related to sepsis epidemiology, treatment, and outcome. 
Additionally, this is the first study to specifically target data about SES in ICU patients with sepsis.

\section{Conclusion}

In this prospective cohort study from Argentina, patients with sepsis and septic shock admitted to public hospitals had remarkably higher mortality in comparison to those in private institutions. Patients from public hospitalswhile younger-were more acutely ill on admission and showed more comorbid conditions; these factors are consistently associated with worse outcomes in sepsis. In addition, a lack of recognition of severity of disease-both by patients and healthcare providers in the public system-might have extended symptom duration and subsequently delayed diagnosis and timely hospital admission. Notwithstanding, sepsis management and human resources were similar in both types of hospitals; however, infections by multiresistant microorganisms, usually associated with increased mortality, were more frequent in public hospitals.

These issues highlight the need for education to raise awareness of sepsis, both within the community and for healthcare personnel. It is also imperative to improve processes of care in the ICU, which are notoriously deficient in Latin-America.

\section{Additional file}

Additional file 1: Table S1. Characteristics of the participating hospitals. Table S2. Localization of the sites of infection in patients in public and private hospitals. Table S3. Bivariable analysis for mortality. Table S4. Full multivariable logistic regression model 1 after multiple imputation. Table S5. Full multivariable logistic regression model 2 after multiple imputation. (DOCX $24 \mathrm{~kb}$ )

\section{Abbreviations}

APACHE II: Acute Physiology And Chronic Health Evaluation II; ARDS: Acute respiratory distress syndrome; BMI: Body mass index; EQ-VAS: Euro-QoL visual analogue scale; GNI: Gross National Income; ICU: Intensive care unit; LMICs: Low- and middle-income countries; SATI: Sociedad Argentina de Terapia Intensiva (Argentine Society of Intensive Care); SES: Socioeconomic status; SOFA: Sequential Organ Failure Assessment

\section{Acknowledgements}

Complete list of SATISEPSIS investigators: Carolina Enrico, Mariel Romitelli (Hospital Zonal Presidente Alvear, Comodoro Rivadavia); Mariel A García, José Celia, Leandro Machuca (Hospital Regional V. Sanguinetti, Comodoro Rivadavia); Fernando Pálizas (Jr.) (Centro Médico Integral Fitz Roy); Mario Pozo (Clínica Bazterrica); Bernardo Latanzio (Clínica Santa Isabel); Emanuel Valgolio, Mario Kenar (Clínica San Camilo); Carlos Sosa, Sergio Sarquis (Hospital de Clinicas); Graciela Tuhay, Francisco Klein (Hospital Universitario Fundación Favaloro); Ariel Sosa, Daniel Ivulich (Hospital Alemán); Luciana Bianchi, Enrique Correger (Hospital Español); Carla Groer, Victoria Arrosagaray (Hospital General de Juan A. Agudos Fernández); Graciela Cueto, Carlos Cozzani (Hospital General de Agudos Cosme Argerich); Gustavo Badariotti, Bernardo de Diego (Sanatorio Mater Dei); Daniela N Vazquez, Gustavo Plotnikov (Sanatorio Anchorena); Analía Santa-María, Mariana Bertes (Sanatorio de la Trinidad Mitre); Alejandro Gomez, María S Santagiuliana (Sanatorio de los Arcos);Margarita Tavela, Pierina Bachetti, Célica Irrazabal (Sanatorio Flemming); Alejandro Risso-Vazquez, Paolo N Rubatto-Birri (Sanatorio Otamendi y Miroli); Gabriel Olarte, Veronica M Cannatelli (Sanatorio
Sagrado Corazón); Anatilde Díaz, Analía García (Hospital Misericordia); Estefanía Minoldo, Cayetano Galletti (Sanatorio Allende Nueva Córdoba); Esteban Payer, Marcelo Avilez (Clínica Modelo S.A); Silvio E Lazzeri, Luis A Huespe (Hospital Escuela Gral. José de San Martín); Lorena A Parra, Fernando Kurban (Hospital del Carmen, Godoy Cruz); Carlos A Pellegrini, Adrian A Martin (Hospital Lagomaggiore, UTI Quemados); Graciela Zakalik, Magalí Sanchez (Hospital Lagomaggiore); Natalia Barreto, Alfredo E Carreras (Hospital General de Agudos Dr. Madariaga, Posadas); Joahana Bastias, Julián Ivacachi (Hospital Provincial Neuquén Castro Rendon); María L Campassi, Fabio G Repetto (Clínica La Pequeña Familia, Junín); María G Saenz, Cecilia Marchena (Hospital Interzonal de Agudos Gral. San Martín, La Plata); María R Marino, Gerardo Ezcurra (HIGA San José de Pergamino); Sebastián Caravaggio, María A García (Hospital El Cruce Nestor Kirchner, Florencio Varela); Ana M Mazzola, Analía Piernatei (Hospital General de Agudos San Felipe, San Nicolás); Estela Molinas, Mauro ladanza (Hospital Isidoro Iriarte, Quilmes); Mario A Traba, Leda F Bacci (Hospital Municipal Dr. Pedro Ecay, Carmen de Patagones); Adriana Fernandez, Damián Piezny, Constanza Arias (Hospital Nacional Prof. Alejandro Posadas, El Palomar, Morón); Gustavo Chaparro, Graciela C Lopez (Instituto Médico Platense, La Plata); Agustín Fernández, Catalina Reyes-Najera (Sanatorio de la Trinidad San Isidro, San Isidro); Adriana Baldiviezo, Alejandra Flores (Sanatorio Itoiz, Avellaneda); Alejandro Risso-Vazquez, Irma Moyano (Sanatorio Las Lomas, San Isidro); Mónica Quinteros, Laura Budrovich (Sanatorio San Lucas); Lilen Corzo, Sebastián A Amieva (Hospital Artemides Zatti, Viedma); Melisa Ré, Nicolás Rocchetti Hospital Escuela Eva Perón (Granadero Baigorria); Juan C Pendino, Lisandro Bettini (Hospital Centenario, Rosario); Lionel Talamonti, Gustavo Izaguirre (Hospital Provincial de Rosario, Rosario); German Schmukler, Ignacio Sabbag (Sanatorio Británico, Rosario); Tomas F Diez, Laura Bergallo (Sanatario Mapaci, Rosario); Cecilia González, Carlos Lovezio (Sanatorio Parque, Rosario); Daniel Duarte, Romina Nicastro (Clínica de Especialidades Médicas Privada, Río Grande); Fernando Bertoletti, Esteban Milioto (Sanatorio San Jorge, Ushuaia).

\section{Authors' contributions}

$E E, J O, A D$, and FP designed the project and the study; EE and AD drafted the manuscript and managed the submission; DV, VE, and FGR contributed to the data analysis and interpretation. All authors included patients. All authors have critically revised the manuscript. All authors have read, reviewed, and approved the final manuscript as submitted.

\section{Funding}

This research was funded by a grant of the National Ministry of Health (2014) given to the Sociedad Argentina de Terapia Intensiva (SATI). The Institution did not have any role in the collection, analysis, and interpretation of the data or in the writing of the manuscript.

\section{Availability of data and materials}

The datasets used/analyzed during the current study are available from the corresponding author on reasonable request.

\section{Ethics approval and consent to participate}

Each local institutional review board assessed and approved the study and established the requirement for patient or his/her surrogate informed consent or a waiver.

\section{Consent for publication}

Not applicable.

\section{Competing interests}

The authors declare that they have no competing interests.

\section{Author details}

${ }^{1}$ Servicio de Terapia Intensiva, Hospital Interzonal de Agudos San Martin de La Plata, Calle 42 No.577, 1900 La Plata, Buenos Aires, Argentina. ${ }^{2}$ Hospital Juan A Fernández, Buenos Aires, Argentina. ${ }^{3}$ Hospital Alemán, Buenos Aires, Argentina. ${ }^{4}$ Hospital Alejandro Posadas, El Palomar, Buenos Aires, Argentina. ${ }^{5}$ Sanatorio Anchorena, Buenos Aires, Argentina. ${ }^{6}$ Clínica Bazterrica, Buenos Aires, Argentina. ${ }^{7}$ Clínica Santa Isabel, Buenos Aires, Argentina. ${ }^{8} \mathrm{Hospital}$ Universitario Fundación Favaloro, Buenos Aires, Argentina. ${ }^{9}$ Sanatorio Otamendi y Miroli, Buenos Aires, Argentina. ${ }^{10}$ Hospital Misericordia, Córdoba, 
Argentina. ${ }^{11}$ Sanatorio de la Trinidad Mitre, Buenos Aires, Argentina

${ }^{12}$ Hospital Lagomaggiore, Mendoza, Argentina.

\section{Received: 5 March 2019 Accepted: 19 June 2019}

Published online: 09 July 2019

\section{References}

1. Havranek EP, Mujahid MS, Barr DA, Blair IV, Cohen MS, Cruz-Flores S, et al. Social determinants of risk and outcomes for cardiovascular disease: a scientific statement from the American Heart Association. Circulation. 2015;132:873-98.

2. Alamian A, Paradis G. Individual and social determinants of multiple chronic disease behavioral risk factors among youth. BMC Public Health 2012;12:224

3. Stringhini S, Carmeli C, Jokela M, Avendaño M, Muennig P, Guida F, et al. Socioeconomic status and the $25 \times 25$ risk factors as determinants of premature mortality: a multicohort study and meta-analysis of 1.7 million men and women. Lancet. 2017;389:1229-37.

4. Egger G, Dixon J. Beyond obesity and lifestyle: a review of 21 st century chronic disease determinants. Biomed Res Int. 2014:2014:731685.

5. World Bank Country and Lending Groups: Country Classification. 2016. https://datahelpdesk.worldbank.org/knowledgebase/articles/906519-worldbank-country-and-lending-groups. Accessed 16 Mar 2017

6. Vincent JL, Marshall JC, Namendys-Silva SA, François B, Martin-Loeches I, et al. Assessment of the worldwide burden of critical illness: the intensive care over nations (ICON) audit. Lancet Respir Med. 2014:2:380-6.

7. Laffey JG, Madotto F, Bellani G, Pham T, Fan E, Brochard L, et al. Geoeconomic variations in epidemiology, patterns of care, and outcomes in patients with acute respiratory distress syndrome: insights from the LUNG SAFE prospective cohort study. Lancet Respir Med. 2017;5:627-38.

8. Fleischmann C, Scherag A, Adhikari N, Hartog CS, Tsaganos T, Schlattmann $P$, et al. Global sepsis incidence and mortality. Am J Respir Crit Care Med. 2016:193:259-72.

9. Dünser MW, Festic E, Dondorp A, Kissoon N, Ganbat T, Kwizera A, et al. Recommendations for sepsis management in resource-limited settings. Intensive Care Med. 2012;38:557-74

10. Shrestha GS, Kwizera A, Lundeg G, Baelani J, LCP A, Pattnaik R, et al. International Surviving Sepsis Campaign guidelines 2016: the perspective from low-income and middle-income countries. Lancet Infect Dis. 2017;17:893-5.

11. Braveman P. Health disparities and health equity: concepts and measurement. Annu Rev Public Health. 2006:27:167-94.

12. Machado FR, Cavalcanti AB, Bozza FA, Ferreira EM, Angotti Carrara FS, Sousa $J$, et al. The epidemiology of sepsis in Brazilian intensive care units (the Sepsis PREvalence Assessment Database, SPREAD): an observational study. Lancet Infect Dis. 2017;17:1180-9.

13. Zhou J, Qian C, Zhao M, Yu X, Kang Y, Ma X, et al. Epidemiology and outcome of severe sepsis and septic shock in intensive care units in mainland China. PLoS One. 2014;9:e107181.

14. Baykara N, Akalın H, Arslantaş MK, Hancı V, Çağlayan C, Kahveci F, et al. Epidemiology of sepsis in intensive care units in Turkey: a multicenter point-prevalence study. Crit Care. 2018;22:93.

15. Arabi YM, Phua J, Koh Y, Du B, Faruq MO, Nishimura M, et al. Asian Critical Care Clinical Trials Group: structure, organization, and delivery of critical care in Asian ICUs. Crit Care Med. 2016:44:e940-8.

16. Braveman P, Egerter S, Williams DR. The social determinants of health: coming of age. Annu Rev Public Health. 2011;32:381-98.

17. Estenssoro E, Alegria L, Murias G, Friedman G, Castro R, Nin Vaeza N, et al. Organizational issues, structure and processes of care in 257 ICUs in Latin America: a study of the Latin America Intensive Care Network. Crit Care Med. 2017:45:1325-36.

18. Londoño JL, Frenk J. Structured pluralism: towards an innovative model for health system reform in Latin America. Health Policy. 1997;41:1-36.

19. Cotlear D, Gómez-Dantés O, Knaul F, Atun R, Barreto ICHC, Cetrángolo O, et al. Universal health coverage in Latin America 2. Overcoming social segregation in health care in Latin America. Lancet. 2015;385:1248-59.

20. Belló M, Becerril-Montekio VM. The health system of Argentina. Salud Publica Mex. 2011;53(Suppl 2):s96-s108.

21. Singer M, Deutschman CS, Seymour CW, Shankar-Hari M, Annane D, Bauer $M$, et al. The third international consensus definitions for sepsis and septic shock (Sepsis-3). JAMA. 2016;315:801-10.
22. Estenssoro E, Kanoore Edul VS, Loudet Cl, Osatnik J, Ríos FG, Vázquez DN, et al. Predictive validity of Sepsis-3 definitions and sepsis outcomes in critically ill patients: a cohort study in 49 ICUs in Argentina. Crit Care Med. 2018;46: 1276-83.

23. Silva E, Pedro M de A, Sogayar AC, Mohovic T, Silva CL, Janiszewski M, et al. Brazilian Sepsis Epidemiological Study (BASES study). Crit Care. 2004;8: R251-60.

24. Vasquez DN, Das Neves AV, Aphalo VB, Loudet Cl, Roberti J, Cicora F, et al. Health insurance status and outcomes of critically ill obstetric patients: a prospective cohort study in Argentina. J Crit Care. 2014;29:199-203.

25. Machado FR, Ferreira EM, Sousa JL, Silva C, Schippers P, Pereira A, et al. Quality improvement initiatives in sepsis in an emerging country: does the institution's main source of income influence the results? An analysis of 21,103 patients. Crit Care Med. 2017:45:1650-9.

26. Estenssoro E, Loudet C, Edul V, Osatnik J, Dubin A, Ríos F, et al. Differences in the outcomes of patients with sepsis and septic shock admitted to either public or private hospitals in Argentina, a lowmiddle income country (LMIC), using Sepsis-3 definitions. Intensive Care Med Exp. 2018;6(Suppl 2):1243.

27. EuroQol Group. EuroQol-a new facility for the measurement of healthrelated quality of life. Health Policy. 1990;16:199-208.

28. Vincent JL, Moreno R, Takala J, Willatts S, De Mendonça A, Bruining H, et al. The SOFA (Sepsis-related Organ Failure Assessment) score to describe organ dysfunction/failure. On behalf of the Working Group on Sepsis-Related Problems of the European Society of Intensive Care Medicine. Intensive Care Med. 1996:22:707-10

29. Atun R, de Andrade LO, Almeida G, Cotlear D, Dmytraczenko T, Frenz P, et al. Universal health coverage in Latin America 1. Health-system reform and universal health coverage in Latin America. Lancet. 2015;385:1230-47.

30. Welch CA, Harrison DA, Hutchings A, Rowan K. The association between deprivation and hospital mortality for admissions to critical care units in England. J Crit Care. 2010;25:382-90.

31. Rush B, Wiskar K, Celi LA, Walley KR, Russell JA, McDermid RC, Boyd JH. Association of household income level and in-hospital mortality in patients with sepsis: a nationwide retrospective cohort analysis. J Intensive Care Med. 2018:33:551-6.

32. Bein T, Hackner K, Zou T, Schultes S, Bösch T, Schlitt HJ, et al. Socioeconomic status, severity of disease and level of family members' care in adult surgical intensive care patients: the prospective ECSSTASI study. Intensive Care Med. 2012:38:612-9.

33. Benaïs $M$, Da Silva $D$, Ferreira $L$, Lainé $L$, Lermuzeaux $M$, Mémain $N$, et al. Socioeconomic status features of ICU patients: the PRECAREA pilot study. Intensive Care Med. 2018:44:2009-11.

34. Thaddeus S, Maine D. Too far to walk: maternal mortality in context. Soc Sci Med. 1994:38:1091-110.

35. Calvello EJ, Skog AP, Tenner AG, Wallis LA. Applying the lessons of maternal mortality reduction to global emergency health. Bull World Health Organ. 2015;93:417-23

36. Karlsen S, Say L, Souza JP, Hogue CJ, Calles DL, Metin Gülmezoglu A, et al. The relationship between maternal education and mortality among women giving birth in health care institutions: analysis of the cross sectional WHO Global Survey on Maternal and Perinatal Health. BMC Public Health. 2011;11:606.

37. Trading economics: Argentina - rural population. https://tradingeconomics. com/argentina/rural-population-percent-of-total-population-wb-data.html. Accessed 3 Dec 2018.

38. Mohr NM, Harland KK, Shane DM, Ahmed A, Fuller BM, Ward MM, et al. Rural patients with severe sepsis or septic shock who bypass rural hospitals have increased mortality: an instrumental variables approach. Crit Care Med. 2017:45:85-93.

39. Conde Pessoa KA, Silva E, Silva CO, Ferreira E, Freitas FG, Castro I, et al. Differences in sepsis treatment and outcomes between public and private hospitals in Brazil: a multicenter observational study. PLoS One. 2013;8:e64790.

40. Assunção M, Akamine N, Cardoso GS, Mello PV, Teles JM, Nunes AL, et al. Survey on physicians' knowledge of sepsis: do they recognize it promptly? J Crit Care. 2010;25:545-52.

41. Kerrigan SW, Martin-Loeches I. Public awareness of sepsis is still poor: we need to do more. Intensive Care Med. 2018:44:1771-3.

42. Poeze M, Ramsay G, Gerlach H, Rubulotta F, Levy M. An international sepsis survey: a study of doctors' knowledge and perception about sepsis. Crit Care. 2004;8:R409-13. 
43. Rhodes A, Evans LE, Alhazzani W, Levy MM, Antonelli M, Ferrer R, et al. Surviving Sepsis Campaign: international guidelines for management of sepsis and septic shock: 2016. Crit Care Med. 2017;45:486-552.

44. Levy MM, Evans LE, Rhodes A. The Surviving Sepsis Campaign bundle: 2018 update. Crit Care Med. 2018:46:997-100.

45. Seymour CW, Gesten F, Prescott HC, Friedrich ME, Iwashyna TJ, Phillips GS, et al. Time to treatment and mortality during mandated emergency care for sepsis. N Engl J Med. 2017;376:2235-44.

46. Sevransky JE, Checkley W, Herrera P, Pickering BW, Barr J, Brown SM, et al. United States Critical IIIness and Injury Trials Group-Critical IIIness Outcomes Study Investigators: protocols and hospital mortality in critically ill patients: the United States critical illness and injury trials group critical illness outcomes study. Crit Care Med. 2015;43:2076-84.

47. Castro R, Nin N, Ríos F, Alegría L, Estenssoro E, Murias G, et al. The practice of intensive care in Latin America: a survey of academic intensivists. Crit Care. 2018;22:39.

48. Penman-Aguilar A, Talih M, Huang D, Moonesinghe R, Bouye K, Beckles G. Measurement of health disparities, health inequities, and social determinants of health to support the advancement of health equity. J Public Health Manag Pract. 2016;22(Suppl 1):S33-42.

49. Improving the prevention, diagnosis and clinical management of sepsis. Seventieth World Health Assembly. Agenda item 12.2 29 May 2017 Available at: http://apps.who.int/gb/ebwha/pdf_files/WHA70/A70_R7-en.pdf. Accessed 11 May 2019

50. Reinhart K, Daniels R, Kissoon N, Machado FR, Schachter RD, Finfer S. Recognizing sepsis as a global health priority-a WHO resolution. N Engl J Med. 2017;377:414-7.

51. Centers for Disease Control and Prevention: get ahead of sepsis. https:// www.cdc.gov/sepsis/get-ahead-of-sepsis/index.html. Accessed 11 May 2019.

52. Damiani E, Donati A, Serafini G, Rinaldi L, Adrario E, Pelaia P, et al. Effect of performance improvement programs on compliance with sepsis bundles and mortality: A systematic review and meta-analysis of observational studies. PLoS One. 2015;10:e0125827.

53. Ministerio de Salud y Accion Social de la Nacion. Available at: http://www. msal.gob.ar/index.php?option=com_ryc_contenidos. Accessed 15 May 2019

54. Na S, Kuan WS, Mahadevan M, Li CH, Shrikhande P, Ray S, et al. Implementation of early goal-directed therapy and the surviving sepsis campaign resuscitation bundle in Asia. Int I Qual Health Care. 2012;24:452-62.

55. Levy MM, Rhodes A, Phillips GS, Townsend SR, Schorr CA, Beale R, et al. Surviving Sepsis Campaign: association between performance metrics and outcomes in a 7.5-year study. Crit Care Med. 2015;43:3-12.

56. Phua J, Koh Y, Du B, Tang YQ, Divatia JV, Tan CC, et al. Management of severe sepsis in patients admitted to Asian intensive care units: prospective cohort study. BMJ. 2011;342:d3245.

\section{Publisher's Note}

Springer Nature remains neutral with regard to jurisdictional claims in published maps and institutional affiliations.

Ready to submit your research? Choose BMC and benefit from:

- fast, convenient online submission

- thorough peer review by experienced researchers in your field

- rapid publication on acceptance

- support for research data, including large and complex data types

- gold Open Access which fosters wider collaboration and increased citations

- maximum visibility for your research: over $100 \mathrm{M}$ website views per year

At BMC, research is always in progress.

Learn more biomedcentral.com/submissions 